\title{
Nutritional Physiology of the Brown Rice Planthopper, Nilaparvata lugens STÅL (Hemiptera: Delphacidae). II. Essential Amino Acids for Nymphal Development
}

\author{
Kenji Koyama \\ Division of Entomology, National Institute of Agro-Environmental \\ Sciences, Yatabe, Tsukuba, Ibaraki 305, Japan
}

(Received April 24, 1985)

\begin{abstract}
Amino acids essential for the growth of $N$. lugens nymphae were investigated. Insects were fed on the synthetic diet MED-1 lacking one amino acid from immediately after hatching. All the $N$. lugens nymphae were able to develop into adults in the absence of any one of the amino acids; therefore no single amino acid is essential for their growth. Growth, however, was markedly delayed in a diet lacking either cysteine, histidine or methionine. The insects developed into adults even when reared on a diet containing neither cystine or cysteine, but all died at the 1st instar when cystine, cysteine and methionine were eliminated from the diet at the same time.
\end{abstract}

\section{INTRODUCTION}

Leafhoppers and planthoppers were first reared on a holidic diet by Koyama and Mitsuhashi (1969), and improvement of the diet and of the rearing method has enabled raising of the following species on such diets; Laodelphax striatellus FAllén (Mitsuhashi and Koyama, 1971), Recilia dorsalis Motschulsky and Nephotettix cincticeps Uhler (Koyama, 1973), Macrosteles fascifrons StÅ (Hou and Brooks, 1975), Nilaparvata lugens Stål (Koyama, 1979), Sogatella furcifera Horváth (Koyama and Mitsuhashi, 1980), and Sogatella longifurcifera Esaki et Ishinara (Koyama et al., 1981). Only a few studies have been made on the nutritional requirements of these insects: on amino acid (Koyama and Mitsuhashi, 1975), vitamin (Koyama and Mrtsuhashi, 1977) and microelement (Koyama and Mitsuhashi, 1979) requirements for nymphal growth of L. striatellus FalléN. For $N$. lugens, the survival period of the larvae on a water solution of several sugars (KoYAma, 1981) and the effect of sugars on nymphal development (Koyama, 1985) has been examined. This paper reports the amino acid requirements of nymphae of $N$. lugens.

\section{MATERIALS AND METHODS}

The $N$. lugens used in this study were originally collected in Saitama Prefecture, and were reared for successive generations in small test tubes since May 1975 on rice seedlings at $25^{\circ} \mathrm{C}$ under $16-\mathrm{hr}$ illumination. The container for rearing them on synthetic diets was the same as reported previously (Koyama, 1979). In all experiments, nym- 
phae were used without contact with rice seedlings. The methods of collecting the eggs and rearing the insects were the same as reported previously (KoyamA, 1979). Each amino acid tested was eliminated from the basic synthetic diet, MED-1, in this study (Table 1.). The insects were reared under long-day condition (16-hr illumination) at $25^{\circ} \mathrm{C}$ throughout the experiment, and the sachet containing the diet was replaced every other day. One hundred individuals were reared in each group, and the number of days required for molting, adult eclosion and death were recorded.

\section{RESULTS}

Figure 1 shows the average nymphal period for $N$. lugens reared on the MED-1 diet from which amino acids had been eliminated one by one. This figure shows that

Table 1. Composition of amino acids in MED-1 diet ( $\mathrm{mg}$ per $100 \mathrm{ml}$ )

\begin{tabular}{lrlr}
\hline L-Alanine & 100 & L-Isoleucine & 200 \\
r-Aminobutyric acid & 20 & L-Leucine & 200 \\
L-Arginine hydrochloride & 400 & L-Lysine hydrochloride & 200 \\
L-Asparagine & 300 & L-Methionine & 100 \\
L-Aspartic acid & 100 & L-Phenylalanine & 100 \\
L-Cysteine & 50 & L-Proline & 100 \\
L-Cystine hydrochloride & 5 & DL-Serine & 100 \\
L-Glutamic acid & 200 & L-Threonine & 200 \\
L-Glutamine & 600 & L-Tryptophan & 100 \\
Glycine & 20 & L-Tyrosine & 20 \\
L-Histidine & 200 & L-Valine & 200 \\
DL-Homoserine & 800 & & \\
\hline
\end{tabular}

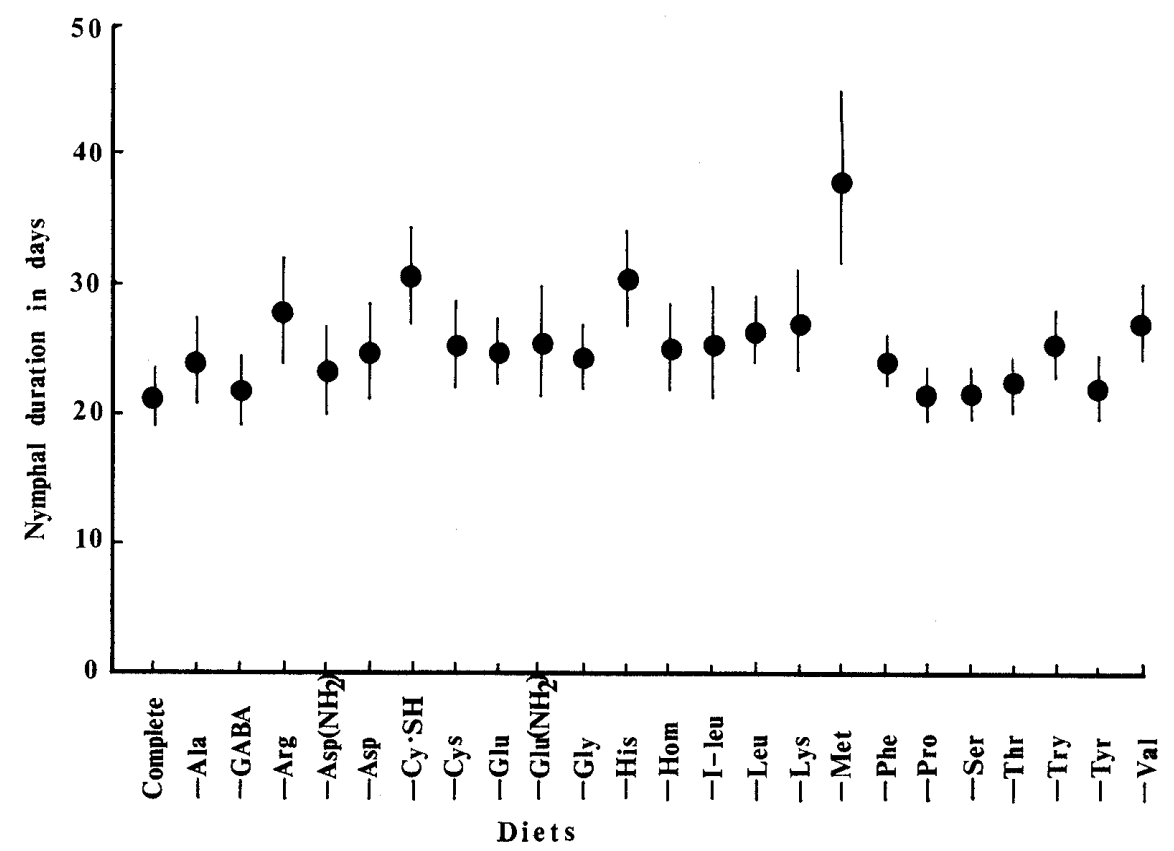

Fig. 1. Nymphal period of $N$. lugens reared on MED-1 diets lacking single amino acids. ф: average \pm standard deviation. 


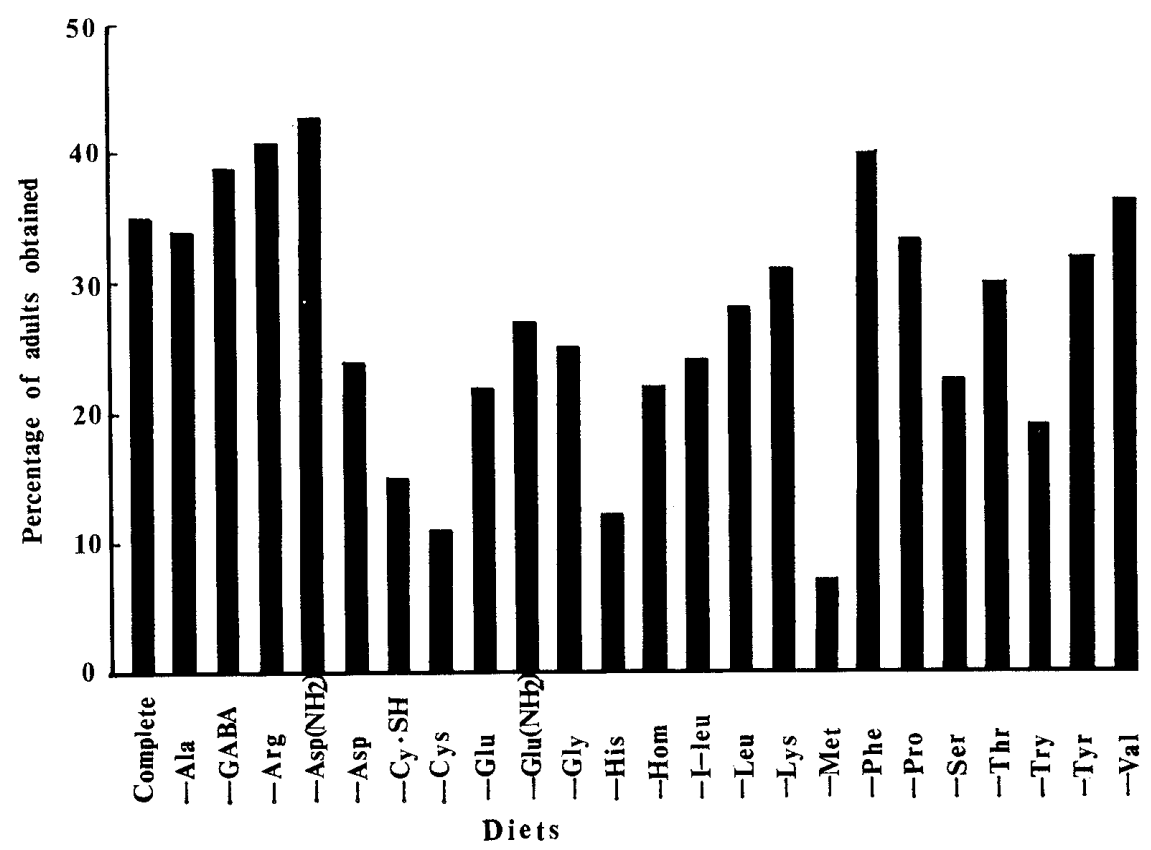

Fig. 2. Adults obtained of $N$. lugens reared on MED-1 diets lacking single amino acids.

Table 2. Survival of $N$. lugens within 19 days after hatching (\%)

\begin{tabular}{lcccccccccc}
\hline & 1 & 3 & 5 & 7 & 9 & 11 & 13 & 15 & 17 & 19 \\
\hline MED-1 & 95 & 62 & 58 & 56 & 55 & 54 & 51 & 44 & 41 & 40 \\
(Complete) & & & & & & & & & & \\
-Ala & 89 & 57 & 52 & 46 & 44 & 43 & 43 & 43 & 41 & 39 \\
-GABA & 93 & 72 & 64 & 58 & 55 & 53 & 52 & 50 & 49 & 46 \\
-Arg & 93 & 75 & 64 & 60 & 57 & 57 & 56 & 56 & 55 & 55 \\
-Asp (NH2) & 95 & 84 & 74 & 65 & 64 & 59 & 55 & 54 & 52 & 51 \\
-Asp & 100 & 75 & 58 & 52 & 47 & 40 & 37 & 34 & 32 & 30 \\
-Cy•SH & 88 & 65 & 49 & 41 & 33 & 29 & 29 & 29 & 29 & 29 \\
-Cys & 85 & 58 & 53 & 46 & 44 & 40 & 39 & 38 & 26 & 22 \\
-Glu & 82 & 48 & 38 & 36 & 33 & 33 & 32 & 29 & 28 & 27 \\
-Gly (NH2) & 92 & 67 & 65 & 53 & 50 & 48 & 45 & 45 & 41 & 36 \\
-Gly & 95 & 55 & 47 & 38 & 36 & 35 & 32 & 30 & 29 & 29 \\
-His & 67 & 34 & 30 & 27 & 24 & 24 & 22 & 21 & 21 & 21 \\
-Hom & 99 & 65 & 62 & 44 & 42 & 37 & 35 & 34 & 34 & 32 \\
-I-leu & 89 & 65 & 45 & 43 & 41 & 40 & 40 & 38 & 38 & 38 \\
-Leu & 91 & 62 & 49 & 40 & 36 & 34 & 34 & 34 & 33 & 33 \\
-Lys & 93 & 59 & 53 & 48 & 42 & 42 & 40 & 40 & 39 & 39 \\
-Met & 88 & 58 & 40 & 29 & 27 & 25 & 19 & 16 & 16 & 15 \\
-Phe & 96 & 74 & 67 & 63 & 60 & 59 & 57 & 56 & 56 & 55 \\
-Pro & 83 & 64 & 59 & 57 & 53 & 50 & 50 & 50 & 48 & 47 \\
-Ser & 89 & 50 & 43 & 39 & 33 & 29 & 28 & 28 & 27 & 27 \\
-Thr & 90 & 63 & 50 & 45 & 44 & 42 & 41 & 40 & 40 & 35 \\
-Try & 94 & 57 & 39 & 34 & 29 & 27 & 25 & 24 & 24 & 24 \\
-Tyr & 91 & 71 & 59 & 52 & 52 & 47 & 47 & 47 & 43 & 40 \\
-Val & 94 & 64 & 51 & 46 & 44 & 43 & 42 & 42 & 42 & 42 \\
-all Amino & & & & & & & & & & \\
acids & 93 & 57 & 42 & 33 & 24 & 11 & 5 & 1 & 0 & \\
& & & & & & & & & \\
-Thy
\end{tabular}


the nymphae developed completely in the absence of any single amino acid. However, the nymphal period was longer when nymphae were reared on a diet lacking cystine, histidine or methionine. The percentage of nymphae developing into adults tended to decrease with an increase in the nymphal period except for those grown without arginine (Fig. 2). Most of the deaths during the nymphal period occurred immediately after hatching. $\quad N$. lugens could survive for only 15 days on a diet that lacked all amino acids (Table 2).

The optimum concentrations of cysteine, cystine which was also examined because cysteine is oxidized into cystine in the diet methionine and histidine were examined, because lack of these amino acids delayed nymphal growth, and decreased the percentage of adult eclosion.

In the absence of both cysteine and cystine, the nymphae were able to grow into adults, but the nymphal period was greatly extended. However, when all 3 sulfurcontaining amino acids, cysteine, cystine and methionine, were eliminated at the same time, all of the nymphae died in the first instar.

Cysteine was not an essential amino acid, but the growth of the nymphae was promoted with the addition of cysteine in the MED-1 diet. Cysteine at a concentration of $1 / 4$ that of the complete MED-1 diet $(12.5 \mathrm{mg} / 100 \mathrm{ml})$ gave the highest percentage of adult eclosion among the concentrations tested (Fig. 3). It was not determined that this concentration was optimum, however, because experiments were not made on cysteine at concentrations of $50 \mathrm{mg} / 100 \mathrm{~m} l$ or more.

Cystine was not an essential amino acid, but in the total absence of cysteine and

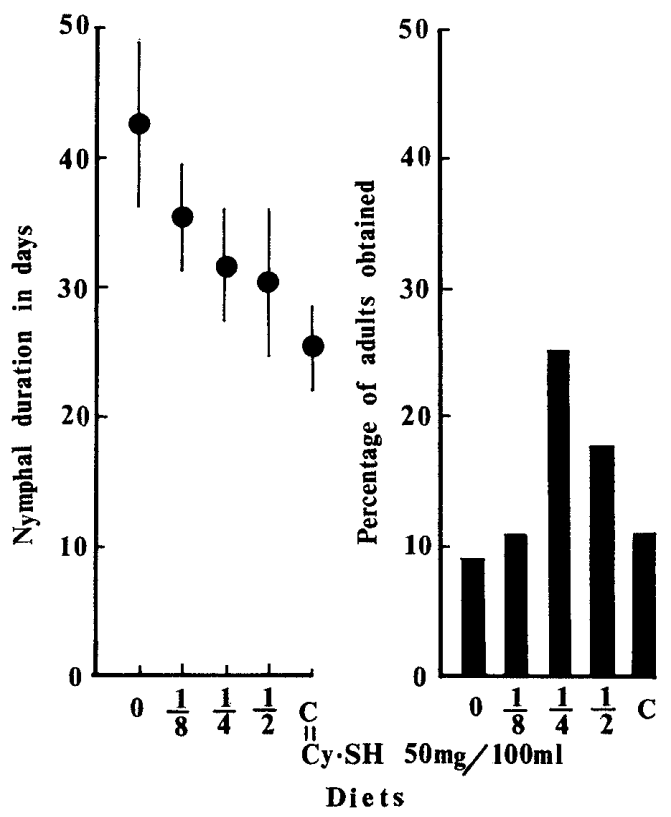

Fig. 3. Effect of the concentration of cysteine in MED-1 diets lacking cystine on nymphal period and percentage of adults obtained. $\quad$ : average \pm standard deviation.



Fig. 4. Effect of the concentration of cystine hydrochloride in MED-1 diet lacking cysteine on nymphal period and percentage of adults obtained. : average \pm standard deviation. 

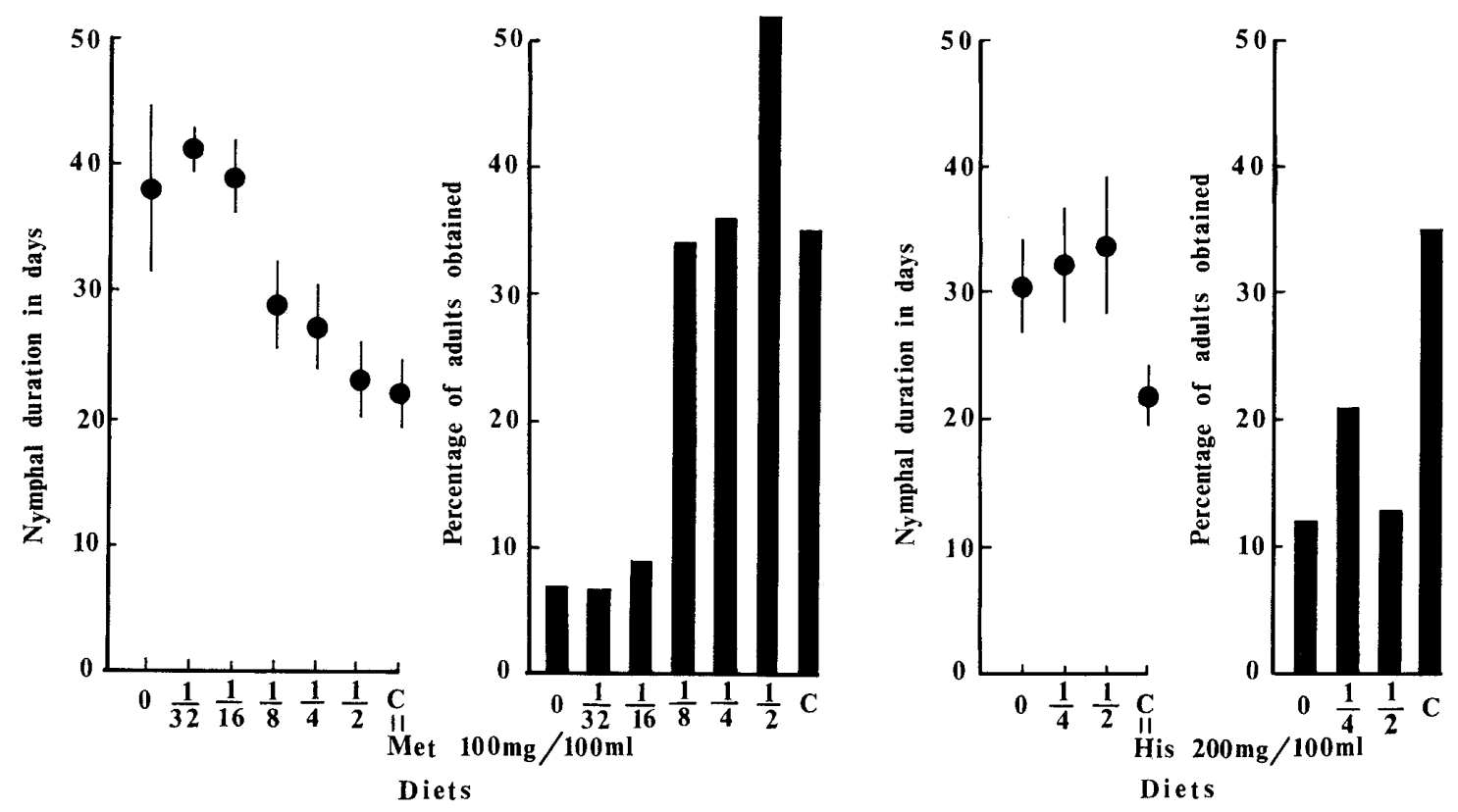

Fig. 5. Effect of the concentration of methionine in MED-1 diet on nymphal duration and percentage of adults obtained. \$: average \pm standard deviation.

Fig. 6. Effect of the concentration of histidine in MED-1 diet on nymphal period and percentage of adults obtained. : average \pm standard deviation.

cystine, the growing period was markedly prolonged, although some nymphae developed into adults. Even when cystine equivalent to $1 / 2$ of the concentration in the complete MED-1 diet was added, growth was not promoted, and the percentage of nymphae developing into adults was still low. The optimum concentration of cystine was presumed to be $5 \mathrm{mg} / 100 \mathrm{ml}$ or more (Fig. 4).

Absence of methionine decreased nymphal survival to below $10 \%$, and nymphal growth was markedly delayed. In the presence of methionine, the growth of the nymphae was promoted, and the percentage of nymphae developing into adults was increased (Fig. 5).

In the absence of histidine growth was delayed, and the percentage of nymphae developing into adults was low. Histidine at less than $1 / 2(100 \mathrm{mg} / 100 \mathrm{ml})$ the concentration of that contained in the complete MED-1 diet did not improve the growth of the nymphae or the percentage developing into adults. The optimum concentration of histidine was estimated to be $200 \mathrm{mg} / 100 \mathrm{ml}$ or more (Fig. 6).

\section{DISCUSSION}

From the experiment in which individual amino acids were eliminated one at a time, it was concluded that no amino acid is essential for the nymphal growth of $N$. lugens. This is very different from other insects whose nutritional requirements have been studied, in many of which the following 10 amino acids are essential; arginine, histidine, isoleucine, leucine, lysine, methionine, phenylalanine, threonine, tryptophane and valine, similar to mammals. Even another species in the same family, L. striatellus, 
required cystine or cysteine and methionine as amino acids essential to the growth of nymphae (Koyama and Mitsuhashi, 1975).

Comparison of the amino acid requirements of $N$. lugens with L. striatellus shows that the nymphae of $L$. striatellus cannot develop into adults in the absence of either cysteine or cystine, whereas $N$. lugens can, even when both substances are deleted from the diet simultaneously. Methionine is also essential for the growth of the nymphae of $L$. striatellus but not for $N$. lugens. All nymphae of both species, however, died at the 1 st instar when these three sulfur-containing amino acids were eliminated from the diet together. These results clearly show what sulfur-containing amino acids are important for the growth of $L$. striatellus and $N$. lugens.

The amino acid requirement of aphids has been examined for Myzus persicae and Aphis fabae. In $M$. persicae, methionine, histidine and isoleucine, have been reported to be essential (DAdD and Krieger, 1968) and for Aphis fabae, alanine, histidine, methionine, proline, serine, cysteine, phenylalanine and tyrosine are said to be necessary (Leckstein and Llewellvn, 1973, 1974). This also shows that amino acid requirements vary even among insects of the same family. Generally, the nutritional requirement of hemiptera is qualitatively smaller than insects of other orders. This might be because of the presence of symbiotic microorganisms which produce the substances essential to the host insect. In $N$. lugens, symbiotic yeast-like organisms are present in the mycetocytes in its abdomen which may be able to produce various substances necessary for growth of the species. It may also be possible that some amino acids can be replaced by others. Lastly, the balance of each amino acid may be important. The elucidation of these points as well as the role of the symbiotic organisms are questions remaining to be answered in the future.

\section{ACKNOWLEDGEMENTS}

The author wishes to express his sincere thanks to Dr. Jun Mitsurashi, Forestry and Forest Products Research Institute, and Dr. Socho NAsu, National Institute of Agro-Environmental Sciences, for their guidance throughout this study. The author is indebted to Dr. David A. Andow, Department of Entomology, University of Minnesota, and Dr. Ken-ichi KısıNo, National Institute of Agro-Environmental Sciences, for their advice on manuscript preparation.

\section{REFERENCES}

DAdD, R. H. and D. L. KRIEger (1968) Dietary amino acid requirements of the aphid, Myzus persicae. J. Insect Physiol. 14: 741-764.

Hou, R. F. and M. A. Brooks (1975) Continuous rearing of the aster leafhopper Macrosteles fascifrons on a chemically defined diet. J. Insect Physiol. 21: 1481-1483.

Koyama, K. (1973) Rearing of Inazuma dorsalis and Nephotettix cincticeps on a synthetic diet. Jap. J. appl. Ent. Zool. 17: 163-166 (in Japanese).

Koyama, K. (1979) Rearing of the brown planthopper, Nilaparvata lugens STAL (Hemiptera: Delphacidae) on a synthetic diet. Jap. J. appl. Ent. Zool. 23: 39-40 (in Japanese).

Koyama, K. (1981) Survival of larvae of the brown planthopper, Nilaparvata lugens ST\&L (Hemiptera: Delphacidae) on sugar solution. Jap. J. appl. Ent. Zool. 25: 125-126 (in Japanese).

Koyama, K. (1985). Nutritional physiology of brown rice planthopper, Nilaparuata lugens STÅL (Hemiptera: Delphacidae). I. Effect of sugars on nymphal development. Appl. Ent. Zool. 20: 292298. 
Koyama, K. and J. Mrtsuhashi (1969) Artificial feeding of smaller brown planthopper, Laodelphax striatellus FAllén (Hemiptera: Delphacidae). Jap. J. appl. Ent. Zool. 13: 8990 (in Japanese).

Koyama, K. and J. Mrtsuhashi (1975) Essential amino acids for the growth of the smaller brown planthopper, Laodelphax striatellus Fallén (Hemiptera: Delphacidae). Appl. Ent. Zool. 10: 208-215.

Koyama, K. and J. Mitsuhashi (1977) Essential vitamins for the nymphal growth of the smaller brown planthopper, Laodelphax striatellus FALLÉN. Jap. J. appl. Ent. Zool. 21:23-26 (in Japanese with an English summary).

Koyama, K. and J. Mitsuhashi (1979) Essential trace metals for the nymphal growth of the smaller brown planthopper, Laodelphax striatellus FALlén. Jap. J. appl. Ent. Zool. 23: 173-177 (in Japanese with an English summary).

Koyama, K. and J. Mitsuhashi (1980) Rearing of the white-backed planthopper, Sogatella furcifera Horváth (Hemiptera: Delphacidae) on a synthetic diet. Jap. J. appl. Ent. Zool. 24: 117-119 (in Japanese).

Koyama, K., J. Mitsuhashi and S. NAsu (1981) Rearing of the planthopper, Sogatella longifurcifera EsaKI et IshrHara (Hemiptera: Delphacidae) on a synthetic diet. Jap. J. appl. Ent. Zool. 25: 198-200 (in Japanese).

Leckstein, P. M. and M. Llewellyn (1973) Effect of dietary amino acid on the size and alary polymorphism of Aphis fabae. J. Insect Physiol. 19: 973-980.

Legkstein, P. M. and M. Llewellyn (1974) The role of amino acids in diet intake and selection and utilization of dipeptides by Aphia fabae. J. Insect Physiol. 20: 877-885.

Mrtsuhashi, J. and K. Koyama (1971) Rearing of planthoppers on a holidic diet. Entomol. Exp. Appl. 14: $93-98$.

Mitsuhashr, J. and K. Koyama (1972) Artificial rearing of the smaller brown planthopper, Laodelphax striatellus FALLÉN, with special reference to rearing conditions for the first instar nymphs. Jap. $J$. appl. Ent. Zool. 16: 8-16 (in Japanese with an English summary). 